\title{
Pengaruh Fasilitas Kerja Terhadap Efektifitas Kerja Pegawai
}

\author{
${ }^{1}$ Ceria Aprilliana, ${ }^{2}$ Yohana Kartika, ${ }^{3}$ Ahmad Irvan Lubis, ${ }^{4}$ Resdi Dorlince Sianturi \\ ${ }^{1-4}$ Program Magister Manajemen, Fakultas Ekonomi, Universitas Islam Sumatera Utara
}

\author{
Article history \\ Received: 12 Jan 2021 \\ Revised: 20 Feb 2021 \\ Accepted: 02 Mar 2021 \\ *Corresponding Author: \\ Ceria Aprilliana, Program \\ Studi Magister Manajemen, \\ Fakultas Ekonomi, \\ Universitas Islam Sumatera \\ Utara \\ Email: \\ ceriaaprilliana@gmail.com
}

\begin{abstract}
Abstrak: Sebagai suatu kebutuhan yang keberadaannya sangat diperlukan, fasilitas akan memberikan kontribusi positif dalam rangka menjalankan suatu bidang usaha untuk mendapatkan manfaat bagi terselenggaranya berbagai macam aktivitas kerja yang dilakukan pegawai. Hal ini bertujuan agar berbagai sarana yang dibutuhkan pegawai dalam bekerja dapat tersedia secara maksimal. Penelitian ini dilakuakan dengan memberikan angket kepada 53 orang responden yang berasal dari Balai Pendidikan dan Pelatihan Pekerjaan Umum dan Perumahan Rakyat, setiap responden menjawab 10 pertanyaan. Kemudian didapatkan hasil yaitu Variabel fasilitas kerja secara parsial tidak ada pengaruh signifikan terhadap efektivitas kerja pegawai di Balai Diklat Pekerjaan Umum dan Perumahan.
\end{abstract}

Kata Kunci : Pengaruh, Fasilitas Kerja, Efektifitas Kerja, Pegawai

\section{PENDAHULUAN}

Kelangsungan hidup dan pertumbuhan dari suatu perusahaan tidak hanya dapat ditentukan dan dinilai dari keberhasilan dalam pengelolaan keuangan, pemasaran serta produknya, tetapi juga dapat ditentukan dari pengelolaan sumber daya manusia (Handoko, 2003). Terlebih lagi dengan adanya fasilitas kerja berupa sarana dan prasarana yang diperlukan untuk membantu pegawai agar lebih mudah menyelesaikan pekerjaan sehingga dapat meningkatkan efektivitas kerjanya (Husnan, 2002). Fasilitas kerja ini merupakan suatu bentuk pelayanan suatu instansi terhadap pegawai agar menunjang efektivitas kerja dalam memenuhi kebutuhan pegawai, sehingga dapat meningkatkan efektivitas kerja kerja pegawai. Adanya fasilitas kerja yang disediakan oleh instansi sangat mendukung pegawai dalam bekerja. Fasilitas kerja tersebut sebagai alat atau sarana dan prasarana untuk membantu pegawai agar lebih mudah menyelesaikan pekerjaan dan pegawai akan bekerja lebih produktif.

Fasilitas kerja memberikan pengaruh positif dan signifikan terhadap efektivitas kerja pegawai (Yuningshi, 2017; Syamsuri, 2009). Sementara itu fenomena yang terjadi di Balai Diklat Pekerjaan Umum dan Perumahan Rakyat Wilayah I Medan bahwa fasilitas kerja yang tersedia kurang mendukung pegawai untuk mempermudah serta membantu dalam proses kerja pegawainya.

Fenomena yang terjadi di Balai Diklat Pekerjaan Umum dan Perumahan Rakyat Wilayah I Medan diantaranya masih relatif lambatnya kemampuan pegawai dalam penyelesaian pekerjaan, dan masih belum sesuainya pekerjaan yang dikerjakan pegawai terhadap apa yang diperintahkan atasan. Maka tujuan dari penelitian ini yaitu untuk mengetahui pengaruh fasilitas kerja terhadap efektivitas kerja pegawai pegawai di Balai Diklat Pekerjaan Umum dan Perumahan Rakyat Wilayah I Medan. 


\section{METODE PENELITIAN}

Pengumpulan data dalam penelitian ini menggunakan pendekatan kuantitatif berlandaskan pada filsafat positivisme, digunakan untuk meneliti pada populasi atau sampel tertentu, teknik pengambilan sampel pada umumnya dilakukan secara random, pengumpulan data menggunakan instrumen penelitian (Sugiyono, 2013). Populasi dalam penelitian ini adalah pegawai di Balai Pendidikan. Dengan teknik penarikan sampel secara total sampling, maka sampel dalam penelitian ini adalah 53 orang pegawai di Balai Pendidikan dan Pelatihan Pekerjaan Umum dan Perumahan Rakyat (1 orang pimpinan tertinggi dan peneliti tidak dilakukan penelitian). Dalam analisa data ini, peneliti akan menganalisis data penelitian secara deskriptif, baik itu data primer maupun data sekunder.

\section{HASIL DAN PEMBAHASAN}

\section{Skor Angket Variabel Fasilitas Kerja}

Tabel 1. Skor Angket Variabel Fasilitas Kerja (X2)

\begin{tabular}{|c|c|c|c|c|c|c|c|c|c|c|c|c|}
\hline \multicolumn{13}{|c|}{$\mathrm{X} 2$} \\
\hline \multirow{3}{*}{ No. } & \multicolumn{12}{|c|}{ ALTERNATIVE JAWABAN } \\
\hline & \multicolumn{2}{|c|}{$\mathbf{a}$} & \multicolumn{2}{|c|}{$\mathbf{b}$} & \multicolumn{2}{|c|}{ c } & \multicolumn{2}{|c|}{ d } & \multicolumn{2}{|c|}{$\mathbf{e}$} & \multicolumn{2}{|c|}{ Jumlah } \\
\hline & $\mathbf{F}$ & $\%$ & $\mathbf{f}$ & $\%$ & $\mathbf{f}$ & $\%$ & $\mathbf{f}$ & $\%$ & $\mathbf{f}$ & $\%$ & $\mathbf{f}$ & $\%$ \\
\hline 1 & 24 & 45,3 & 29 & 54,7 & 0 & 0,0 & 0 & 0,0 & 0 & 0,0 & 53 & 100,0 \\
\hline 2 & 16 & 30,2 & 35 & 66,0 & 2 & 3,8 & 0 & 0,0 & 0 & 0,0 & 53 & 100,0 \\
\hline 3 & 20 & 37,7 & 32 & 60,4 & 1 & 1,9 & 0 & 0,0 & 0 & 0,0 & 53 & 100,0 \\
\hline 4 & 14 & 26,4 & 38 & 71,7 & 1 & 1,9 & 0 & 0,0 & 0 & 0,0 & 53 & 100,0 \\
\hline 5 & 22 & 41,5 & 31 & 58,5 & 0 & 0,0 & 0 & 0,0 & 0 & 0,0 & 53 & 100,0 \\
\hline 6 & 18 & 34,0 & 34 & 64,2 & 1 & 1,9 & 0 & 0,0 & 0 & 0,0 & 53 & 100,0 \\
\hline 7 & 11 & 20,8 & 31 & 58,5 & 11 & 20,8 & 0 & 0,0 & 0 & 0,0 & 53 & 100,0 \\
\hline 8 & 19 & 35,8 & 32 & 60,4 & 2 & 3,8 & 0 & 0,0 & 0 & 0,0 & 53 & 100,0 \\
\hline 9 & 16 & 30,2 & 31 & 58,5 & 6 & 11,3 & 0 & 0,0 & 0 & 0,0 & 53 & 100,0 \\
\hline 10 & 11 & 20,8 & 42 & 79,2 & 0 & 0,0 & 0 & 0,0 & 0 & 0,0 & 53 & 100,0 \\
\hline
\end{tabular}

Dari angket yang diberikan kepada 53 orang responden, setiap responden menjawab 10 pertanyaan. Maka penulis mentabulasi hasil jawaban angket untuk variabel fasilitas kerja, dengan rincian skor pada Tabel 1 diatas.

\section{Uji Validitas}

Tabel 2. Hasil Uji Validitas Variabel $\left(\mathrm{X}_{2}\right)$

\begin{tabular}{|c|c|c|c|}
\hline Nomor Soal & r-hitung & r-tabel & Keterangan \\
\hline 1 & 0,646 & 0,271 & Valid \\
\hline 2 & 0,772 & 0,271 & Valid \\
\hline 3 & 0,756 & 0,271 & Valid \\
\hline 4 & 0,687 & 0,271 & Valid \\
\hline 5 & 0,713 & 0,271 & Valid \\
\hline 6 & 0,726 & 0,271 & Valid \\
\hline 7 & 0,436 & 0,271 & Valid \\
\hline
\end{tabular}




\begin{tabular}{|c|c|c|c|}
\hline Nomor Soal & r-hitung & r-tabel & Keterangan \\
\hline 8 & 0,657 & 0,271 & Valid \\
\hline 9 & 0,731 & 0,271 & Valid \\
\hline 10 & 0,607 & 0,271 & Valid \\
\hline
\end{tabular}

Pengujian validitas instrumen menggunakan Analyst Correlate Bivariate untuk mencari correlation coefficient dari Product Moment Pearson dengan SPSS. Kemudian dibandingkan dengan nilai r-tabel untuk $\alpha=0.05$ dengan derajat kebebasan $(\mathrm{dk}=\mathrm{n}-2)$ sehingga didapat $r$-tabel. Untuk butir pernyataan dengan nilai koefisien korelasi r-hitung > rtabel maka butir pernyataan tersebut dinyatakan valid. Karena jumlah responden yang digunakan untuk uji validitas sebanyak 53 orang, maka nilai r-tabel dapat ditentukan dari:

$\mathbf{d k}=\mathbf{n}-\mathbf{2}=\mathbf{5 3 - 2}=\mathbf{5 1}$.

Nilai r-tabel dengan $\mathrm{dk}=51$ adalah 0,271. Jadi, jika r-hitung $>\mathbf{0 , 2 7 1}$ maka item pertanyaan dinyatakan valid.

\section{Uji Reliabilitas}

Tabel 3. Hasil Uji Reliabilitas Variabel

\begin{tabular}{|c|c|c|c|}
\hline Variable & $\begin{array}{c}\text { Cronbach's } \\
\text { Alpha }\end{array}$ & N of Items & Reliabilitas Status \\
\hline $\mathrm{X}_{1}$ & 0,845 & 10 & Reliabel \\
\hline $\mathrm{X}_{2}$ & 0,859 & 10 & Reliabel \\
\hline $\mathrm{X}_{3}$ & 0,895 & 10 & Reliabel \\
\hline $\mathrm{Y}$ & 0,838 & 10 & Reliabel \\
\hline
\end{tabular}

Berdasarkan tabel 3 diatas terlihat bahwa nilai Cronbach Alpha seluruh variabel berkisar antara 0 sampai 1 dan lebih cenderung mendekati angka 1, dengan demikian keseluruhan item dalam instrumen pengukuran dapat kategorikan sangat reliabel.

\section{Uji Normalitas}

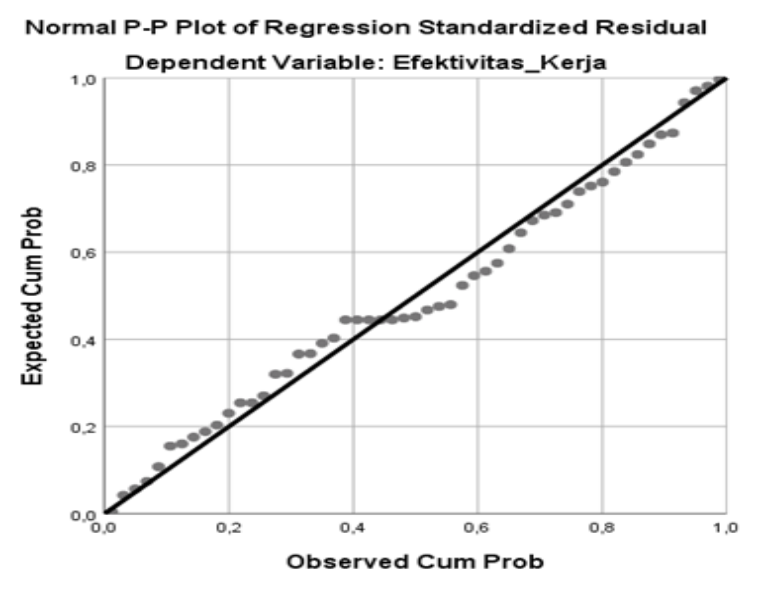

Gambar 1. Normalitas Data

Pada output SPSS seperti Gambar 1. diatas diketahui bagian normal P-P Plot of Regresion Standardized Residual, dapat dijelaskan bahwa data-data (titik-titik) cenderung lurus mengikuti garis diagonal sehingga data dalam penelitian ini cenderung berdistribusi normal. 


\section{Uji Multikolinearitas}

Menurut Santoso (2004:203), pada umumnya jika VIF lebih besar dari 5, maka variabel bebas tersebut mempunyai persoalan multikolinearitas dengan variabel bebas lainnya. Pada ouput SPSS bagian tabel Coefficient diatas, semua angka VIF berada diatas 5, hal ini menunjukan tidak terjadi multikolinearitas.

Tabel 4. Uji Multikolinearitas

\section{Coefficients $^{\mathrm{a}}$}

\begin{tabular}{|c|c|c|c|c|c|c|c|c|}
\hline & \multirow[t]{2}{*}{ Model } & \multicolumn{2}{|c|}{$\begin{array}{l}\text { Unstandardized } \\
\text { Coefficients }\end{array}$} & \multirow{2}{*}{$\begin{array}{c}\text { Standardized } \\
\text { Coefficients } \\
\text { Beta }\end{array}$} & \multirow[t]{2}{*}{$\mathrm{t}$} & \multirow[t]{2}{*}{ Sig. } & \multicolumn{2}{|c|}{$\begin{array}{l}\text { Collinearity } \\
\text { Statistics }\end{array}$} \\
\hline & & $\mathrm{B}$ & Std. Error & & & & Tolerance & VIF \\
\hline \multirow{4}{*}{1} & (Constant) & 8,409 & 3,801 & & 2,212 & ,032 & & \\
\hline & Kec_Intelektual & ,298 & ,098 & ,306 & 3,025 & ,004 & 627 & 1,594 \\
\hline & Fas_Kerja &, 055 & ,096 & ,058 & ,568 &, 572 & 614 & 1,630 \\
\hline & Bud_Organisasi & ,444 & ,085 &, 572 & 5,231 &, 000 & ,537 & 1,863 \\
\hline
\end{tabular}

a. Dependent Variable: Efektivitas_Kerja

\section{Uji Heteroskedastisitas}

Pola Scatterplot seperti pada gambar dibawah, terlihat titk-titik menyebar secara acak, tidak membentuk sebuah pola tertentu yang jelas, serta tersebar baik diatas maupun dibawah angka nol pada sumbu Y. Hal ini berarti tidak terjadi heteroskedastisitas pada model regresi, sehingga model regresi layak dipakai

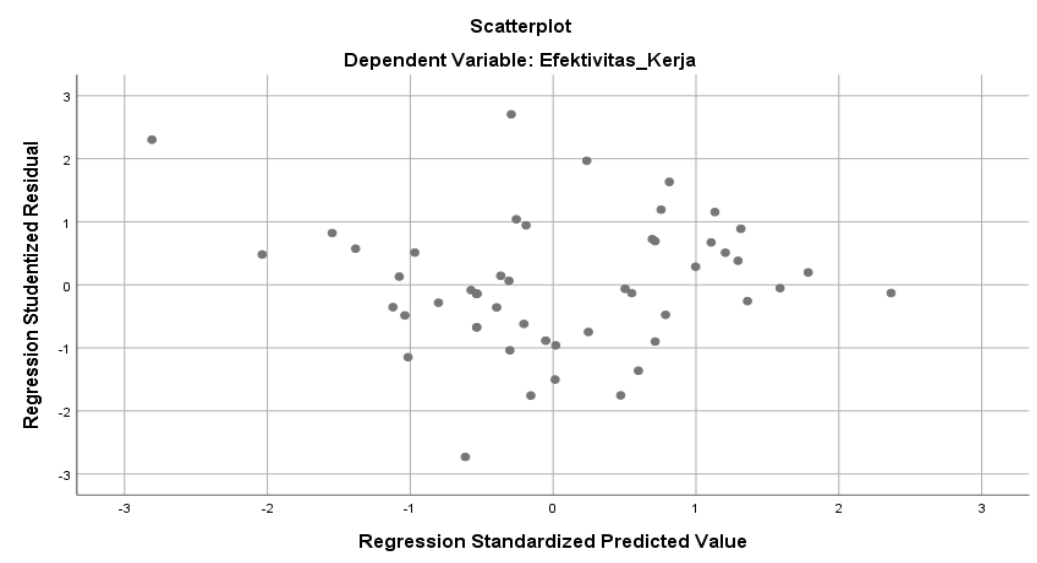

Gambar 2. Uji Heteroskedastitas

\section{Analisis Regresi Liniear Berganda}

Untuk mempermudah dalam evaluasi data ini, maka penulis mencari nilai-nilai yang dibutuhkan dengan menggunakan perangkat lunak komputer yaitu program SPSS dengan hasil data seperti pada tabel 5.12 diatas maka diperoleh hasil sebagai berikut:

$$
\mathrm{Y}=8,409+0,298 \mathrm{X}_{1}+0,055 \mathrm{X}_{2}+0,444 \mathrm{X}_{3}+\varepsilon
$$

Pada persamaan diatas bahwa koefesien $\mathrm{X}_{2}$ (Fasilitas Kerja) memiliki nilai positif yaitu 0,055 . Hal ini menunjukan bahwa variabel fasilitas kerja mempunyai pengaruh positif 
terhadap Efektivitas Kerja di Balai Diklat Pekerjaan Umum dan Perumahan Rakyat Wilayah I Medan.

\section{Pengujian Simultan (Uji F)}

Pada tabel 5. dibawah terlihat bahwa nilai F-hitung adalah 35,572 dan nilai signifikansi 0,000. Dengan derajat bebasnya yaitu $\mathrm{df}_{1}=\mathrm{k}-1=4-1=3$ dan $\mathrm{df}_{2}=\mathrm{N}-\mathrm{k}=53$ - $4=49$, maka nilai F-tabel dengan tingkat kepercayaan $95 \%(\alpha: 0,05)$ adalah $\mathbf{2 , 7 9}$.

Sehingga nilai F-hitung > F-tabel $(35,572>2,79)$ dan dengan nilai signifikansi $0,000<0,05$ maka Ha diterima dan Ho ditolak berarti hipotesis dalam penelitian ini yaitu bahwa Fasilitas Kerja secara simultan berpengaruh signifikan terhadap Efektivitas Kerja Pegawai dalam bekerja di Balai Diklat Pekerjaan Umum dan Perumahan Rakyat Wilayah I Medan.

Tabel 5. Tabel Anova ANOVA $^{\mathrm{a}}$

\begin{tabular}{clc|c|c|c|c} 
& Model & Sum of Squares & df & Mean Square & F & Sig. \\
\hline \multirow{2}{*}{1} & Regression & 392,213 & 3 & 130,738 & 35,572 &, $000^{\text {b }}$ \\
\hline & \begin{tabular}{llllll} 
Residual \\
\cline { 2 - 7 }
\end{tabular} & 180,089 & 49 & 3,675 & & \\
\hline
\end{tabular}

a. Dependent Variable: Efektivitas_Kerja

b. Predictors: (Constant), Bud_Organisasi, Kec_Intelektual, Fas_Kerja

\section{Pengujian Parsial (Uji t)}

Untuk mengetahui secara parsial pengaruh Fasilitas Kerja terhadap Efektivitas Kerjadalam bekerja dapat dilihat pada tabel 5.15 diatas. Berdasarkan tabel tersebut diperoleh nilai t-hitung sebesar 0,568. Sedangkan nilai t-tabel pada tingkat kepercayaan $95 \%(\alpha: 0,05)$ adalah 2,009.

Berdasarkan nilai t-hitung < t-tabel $(0,568<2,009)$, maka dapat disimpulkan maka Ho diterima dan Ha ditolak, yang artinya variabel Fasilitas Kerja secara parsial tidak ada pengaruh signifikan terhadap Efektivitas Kerja di Balai Diklat Pekerjaan Umum dan Perumahan Rakyat Wilayah I Medan.

Tabel 6. Hasil Uji Parsial Fasilitas Kerja Terhadap Efektivitas Kerja Pegawai

\section{Coefficients $^{\mathrm{a}}$}

\begin{tabular}{cccccccc} 
Model & \multicolumn{2}{c}{$\begin{array}{c}\text { Unstandardized } \\
\text { Coefficients }\end{array}$} & \multicolumn{2}{c}{$\begin{array}{c}\text { Standardized } \\
\text { Coefficients }\end{array}$} & t & Sig. & \multicolumn{2}{c}{$\begin{array}{c}\text { Collinearity } \\
\text { Statistics } \\
\text { B }\end{array}$} & Std. Error & Beta & & & Tolerance & VIF \\
\hline Fas_Kerja &, 055 &, 096 &, 058 &, 568 &, 572 &, 614 & 1,630 \\
\hline
\end{tabular}

a. Dependent Variable: Efektivitas_Kerja

Sumber : Output SPSS, diolah 2020

\section{Pengujian Koefisien Determinasi}

Pada Tabel 7 dibawah menunjukan nilai Adjusted $\mathrm{R}^{2}$ adalah 66,6\% variabel Efektivitas Kerja dalam bekerja di Balai Diklat Pekerjaan Umum dan Perumahan Rakyat Wilayah I 
Medan dapat dijelaskan oleh variabel Fasilitas Kerja sedangkan sisanya sebesar 33,4\% tidak dilakukan dalam penelitian ini.

Tabel 7. Model Summary

Model Summary

\begin{tabular}{cc|c|c|c} 
Model & $\mathrm{R}$ & R Square & Adjusted R Square & $\begin{array}{c}\text { Std. Error of the } \\
\text { Estimate }\end{array}$ \\
\hline 1 &, $828^{\mathrm{a}}$ &, 685 &, 666 & 1,91710 \\
\hline
\end{tabular}

a. Predictors: (Constant), Bud_Organisasi, Kec_Intelektual, Fas_Kerja

b. Dependent Variable: Efektivitas_Kerja

Sumber : Output SPSS, diolah 2020

\section{KESIMPULAN}

Adapun yang menjadi kesimpulan dari penelitian ini adalah sebagai berikut :

Variabel fasilitas kerja secara parsial tidak ada pengaruh signifikan terhadap efektivitas kerja pegawai di Balai Diklat Pekerjaan Umum dan Perumahan Rakyat Wilayah I Medan. Nilai Adjusted R Square adalah 0,666 atau 66,6\% yang artinya efektivitas kerja pegawai di Balai Diklat Pekerjaan Umum dan Perumahan Rakyat Wilayah I Medan dapat dijelaskan oleh variabel fasilitas kerja sedangkan sisanya sebesar 33,4\% tidak dilakukan dalam penelitian ini.

\section{DAFTAR PUSTAKA}

Abd. Rasyid Syamsur., 2009. Analisis Disiplin Dan Fasilitas Kerja Terhadap Efektivitas Kerja Pegawai.

Fenti Yuningshi. 2017. Analisis Pengaruh Fasilitas Kerja Dan Beban Kerja Terhadap Efektivitas Kerja Pegawai pada Inspektorat Kabupaten Bangka Tengah.

Handoko, T. Tani. 2003. Manajemen Personalia dan Sumber Daya Manusia. Edisi Kedua. Yogyakarta : BPPE.

Husnan, Suad. 2002. Manajemen Personalia. Edisi Keempat Yogyakarta : BPFE.

Santoso, Singgih. 2004. Mengatasi Berbagai Masalah Statistik dengan SPSS Versil1.5. Jakarta: Elex Media Komputindo.

Sugiyono. 2013. Metodelogi Penelitian Kuantitatif, Kualitatif Dan R\&D. Bandung: ALFABETA. 